\title{
Experimental Study of Impact-Protective Elements for Unidirectional Ribs of Lattice Composite Aircraft Structures
}

\author{
Andrey Chernov $^{1, *}$, Ivan Kondakov ${ }^{1}$ and Yury Mirgorodskiy ${ }^{1}$ \\ ${ }^{1}$ Central Aerohydrodynamic Institute, 1 Zhukovsky St., Zhukovsky, Moscow Region, Russia
}

\begin{abstract}
Lattice structures based on unidirectional composite ribs is currently one of the most promising directions of research aiming to create lightweight and reliable structure of future aircrafts [1]. Hybrid structure concepts based on lattice layouts have been developed for a number of conventional and non-conventional civil aircraft configurations, giving up to $15-20 \%$ weight saving as compared to conventional composite structures based on laminated skin and stiffeners [2]. One of the most critical problems of load-bearing lattice composite structures is very high sensitivity to impact loads, which is even more crucial than for the laminated composite structures. At the same time, topology of lattice grid makes it possible to create reliable protective system for the ribs, which can be effective in terms of weight expenses.
\end{abstract}

\section{Multilevel protection system of the loadbearing rib of lattice composite fuselage structure}

The impact resistance requirements for a rib composite structure can be satisfied by providing a reliable protection system for the loadbearing ribs against impact influence. The internal impact (tool drop during maintenance) and the external impact (hail, small stones from under the wheels) can occur with fuselage structure. Therefore the main protective elements should be applied only on the faces of the loadbearing ribs adjacent to the outer/inner skin.

Impact, which can experience aircraft structures in operation fall, as a rule, either on the outer shell of the compartment (hail, small stones from under the chassis, etc.), or on the inner shell (tool drop during maintenance) [3]. Therefore, the main protective elements should be applied only on the faces of the power ribs adjacent to the outer/inner shell.

In addition to the rib protection, for many structures there is a need to maintain internal tightness under impact. For this reason, it have to be ensured that there is no through penetration when impact occur on the structure. Fig. 1 illustrates one of the possible variant of protection system for loadbearing rib [4].

\footnotetext{
${ }^{*}$ Corresponding author: andcherr@rambler.ru
} 


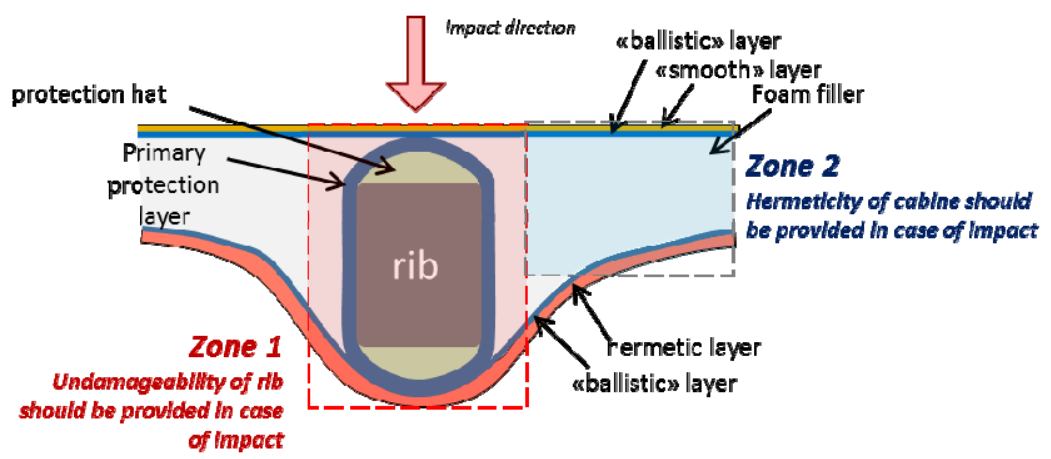

Fig. 1. Principal scheme of multilevel protection system for loadbearing rib

\section{Experimental study}

In frame of this work the protection system effectiveness for lattice composite rib structures were performed. Elementary specimens of composite unidirectional rib with protection hat and primary protection layer were manufactured (see Fig. 2).

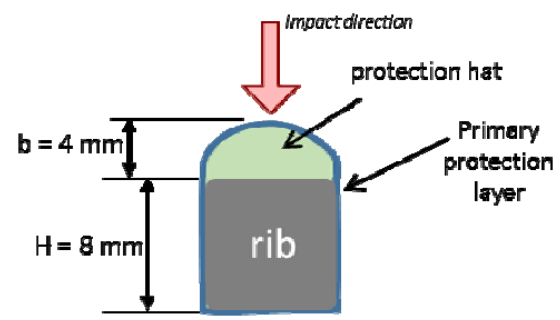

Fig. 2. Test specimen scheme

Specimens of the ribs were made by winding composite technology. The protective hats were made of ABS plastic by additive method and fixed on the samples with an elastic band. The samples of ribs had a square cross-section on the side $\mathrm{H}=8 \mathrm{~mm}$, protective caps were made in several versions with different heights and porosity of the internal structure

Experimentol samples

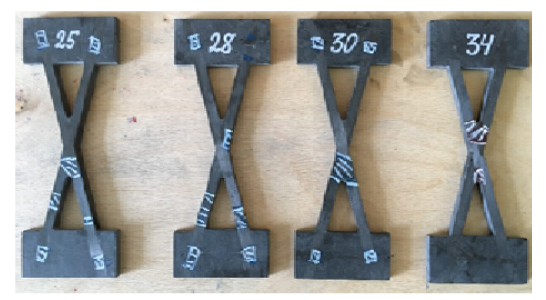

Protection hats

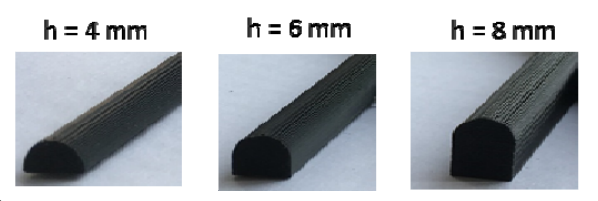

(see Fig. 3). 
Fig. 3. Specimens of test composite ribs and protection hats

Tests of each of the samples were carried out according to the following procedure:

- Input non-destructive testing (ultrasound investigation)

- Installation of a protective cap on the sample and winding with an elastic band

- Installation of the specimen in the locking device

- Application of impact damage

- $\quad$ Removing protective elements

- Output non-destructive testing (ultrasound investigation)

Impact damage was applied by the Instron impact test machine Dynatup $9250 \mathrm{HV}$ [3]. Fig. 4 illustrates of boundary condition of the specimen on the test table. A system of bars and plates was used to prevent the horizontal specimen displacements.

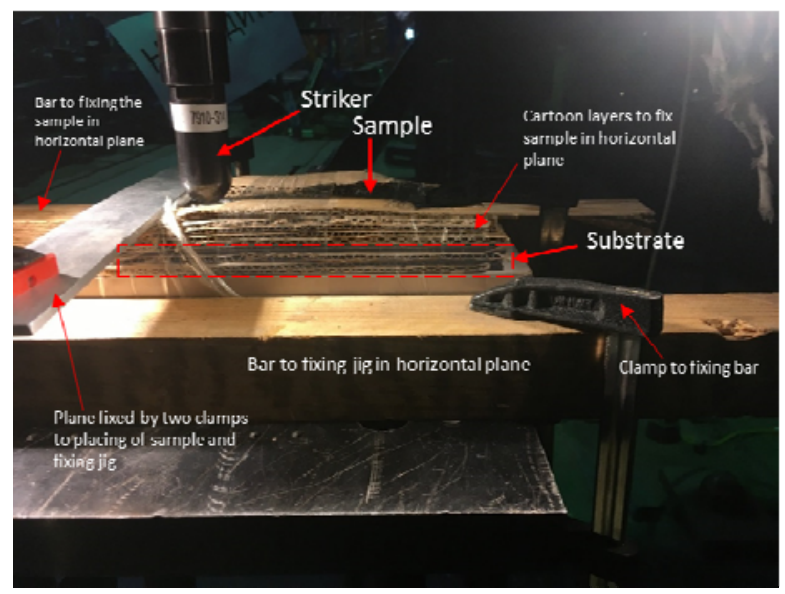

Fig. 4. Specimen fixing in test machine

It was experimentally established that the 30 Joules impact leads $3400 \mathrm{~N}$ contact force. For determination of real specimen displacements in full-scale fuselage compartment under impact loading the finite element analysis of lattice composite fuselage barrel (diameter is $4 \mathrm{~m}$ ) were performed. According these finite element analysis results the carton substrate to simulate the real displacement was chosen for test of elementary rib specimens (See Fig. 4 and 5).
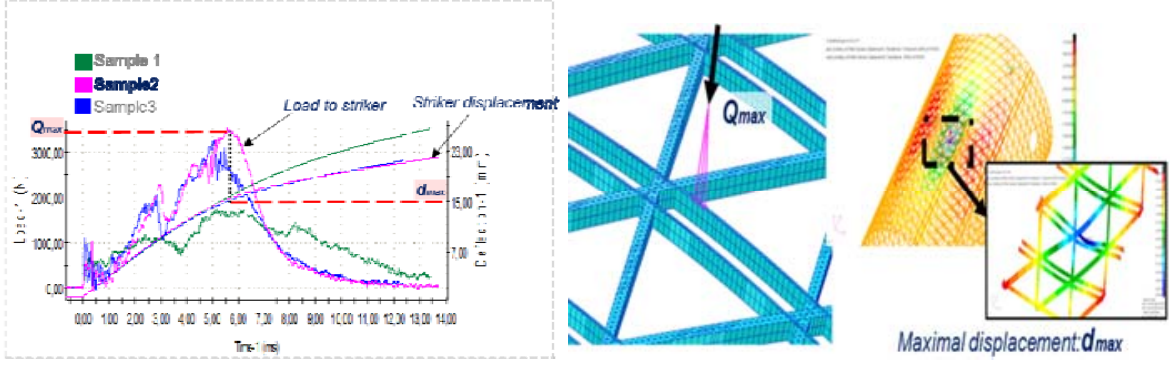

Fig. 5. Experimental investigation to define parameters of substrate which simulate real stiffness of lattice structure correctly 
The Fig. 6 illustrates an example of a sample test results. The $30 \mathrm{~J}$ impact on the unprotected rib is almost completely destroyed, whereas for the protected rib only the protective cap is damaged, and no damage is visible on the surface of the rib itself. After each of the tests, ultrasonic nondestructive testing of the samples was carried out, and the weight of the protection system (protective cap and elastic winding) was determined. During investigation, the dependence of protection degree of the rib on the weight of the protection system was assessed. In these dependencies, the weight of the protective elements was determined as a percentage of the rib weight. The weight of the rib was determined by the geometric parameters of the sample (excluding fixing part) and the known values of the specific weight of the lattice composite structures.
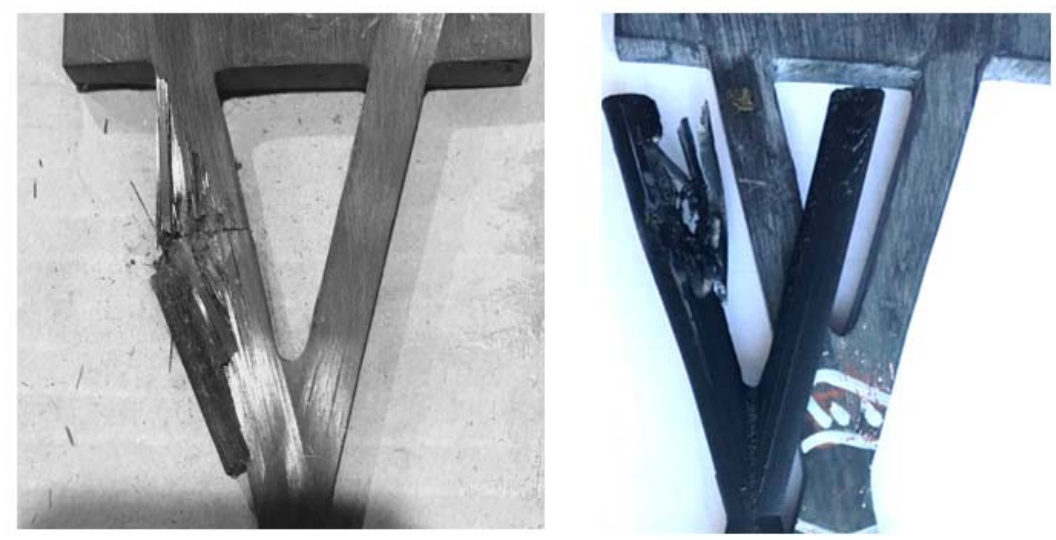

Fig. 6. Test samples after $30 \mathrm{~J}$ impact without protection (on the left) and with protection hat (on the right)

\section{Conclusions}

The protection system for lattice composite rib structures based on additive 3-D printing technology the most promising way for creation light weight protection system. In this paper the first generation of protect elements based on 3-D printing technology was presented. The weight efficiency such kind of considered protection system are shown in Fig. 7. Diagram illustrate to fully protect a unidirectional composite rib from a "certified" $50 \mathrm{~J}$ impact, you will need to "add" about $90 \%$ of the weight to protect this rib, to protect against a "certified" impact of $35 \mathrm{~J}$ - about $40 \%$. Thus, further research will be directed to develop more multistage and energy absorb protection system need to be create. 


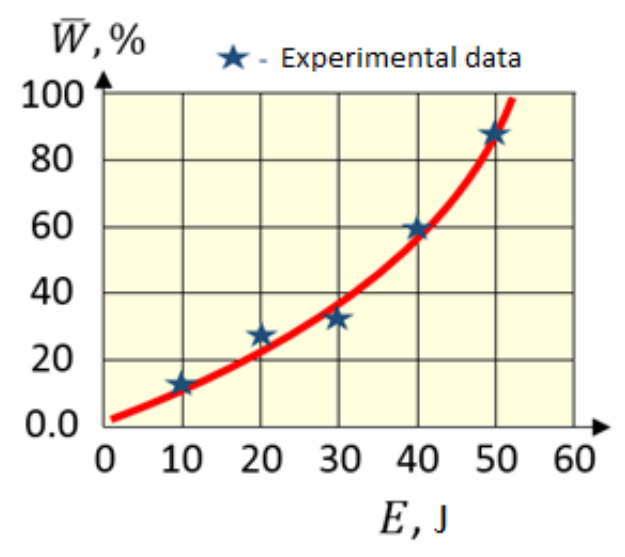

Fig. 7. Weight of protection elements (in percentage of rib weight) necessary for full protection of the rib in dependence of impact energy

\section{References}

1. Vasiliev V and Razin A. Anisogrid composite lattice structures for spacecraft and aircraft applications. Composite Structures, 76, pp.182-189, 2006

2. Shanygin A, Dubovikov, E, Fomin V, Mareskin I, Zichenkov M. Designing pro-composite truss layout for load-bearing aircraft structures. Fatigue and Fracture of Engineering Materials and Structures. 2017; 40:1612-1623. https://doi.org/10.1111/ffe.12695

3. International Air Transportation Association 2005, "Ground Damage Prevention Programme Targets 10\% Cost Reduction," Industry Times, Edition 7, September, Article 4.

4. E.A. Dubovikov, M.C. Zichenkov, I.V. Mareskin, A.V. Chernov, A.N. Shanygin. Investigation of synergetic effect influence on strength characteristics and weight efficiency of load-bearing aviation structures//Proceedings of the 31 st International Congress of the Aeronautical Sciences. Belo Horisonte. September. 2018 